University of Nebraska - Lincoln

DigitalCommons@University of Nebraska - Lincoln

Roman L. Hruska U.S. Meat Animal Research

U.S. Department of Agriculture: Agricultural Center

Research Service, Lincoln, Nebraska

4-1-2021

\title{
Characterization of the domestic goat yठ T cell receptor gene loci and gene usage
}

\author{
Alexandria Gillespie \\ University of Massachusetts Amherst \\ Al Yirsaw \\ University of Massachusetts Amherst \\ Karthick P. Gunasekaran \\ University of Massachusetts Amherst \\ Timothy P. L. Smith \\ USDA, Animal Research Center, tim.smith@usda.gov \\ Derek M. Bickhart \\ USDA ARS U.S. Dairy Forage Research Center
}

See next page for additional authors

Follow this and additional works at: https://digitalcommons.unl.edu/hruskareports

Part of the Beef Science Commons, and the Meat Science Commons

Gillespie, Alexandria; Yirsaw, Al; Gunasekaran, Karthick P.; Smith, Timothy P. L.; Bickhart, Derek M.; Turley, Michael; Connelley, Timothy; Telfer, Janice C.; and Baldwin, Cynthia L., "Characterization of the domestic goat $ү \delta$ T cell receptor gene loci and gene usage" (2021). Roman L. Hruska U.S. Meat Animal Research Center. 552.

https://digitalcommons.unl.edu/hruskareports/552

This Article is brought to you for free and open access by the U.S. Department of Agriculture: Agricultural Research Service, Lincoln, Nebraska at DigitalCommons@University of Nebraska - Lincoln. It has been accepted for inclusion in Roman L. Hruska U.S. Meat Animal Research Center by an authorized administrator of DigitalCommons@University of Nebraska - Lincoln. 


\section{Authors}

Alexandria Gillespie, Al Yirsaw, Karthick P. Gunasekaran, Timothy P. L. Smith, Derek M. Bickhart, Michael Turley, Timothy Connelley, Janice C. Telfer, and Cynthia L. Baldwin 


\title{
Characterization of the domestic goat $\gamma \delta \mathrm{T}$ cell receptor gene loci and gene usage
}

\author{
Alexandria Gillespie ${ }^{1} \cdot$ Al Yirsaw $^{1} \cdot$ Karthick P. Gunasekaran ${ }^{2} \cdot$ Timothy P. Smith $^{3}$ - Derek M. Bickhart ${ }^{4}$. \\ Michael Turley ${ }^{1} \cdot$ Timothy Connelley $^{5}$. Janice C. Telfer ${ }^{1}$. Cynthia L. Baldwin ${ }^{1}$
}

Received: 16 November 2020 / Accepted: 2 January 2021 / Published online: 21 January 2021

(c) The Author(s), under exclusive licence to Springer-Verlag GmbH, DE part of Springer Nature 2021

\begin{abstract}
Goats and cattle diverged 30 million years ago but retain similarities in immune system genes. Here, the caprine $\mathrm{T}$ cell receptor (TCR) gene loci and transcription of its genes were examined and compared to cattle. We annotated the TCR loci using an improved genome assembly (ARS1) of a highly homozygous San Clemente goat. This assembly has already proven useful for describing other immune system genes including antibody and leucocyte receptors. Both the TCR $\gamma$ (TRG) and TCR $($ TRD) loci were similarly organized in goats as in cattle and the gene sequences were highly conserved. However, the number of genes varied slightly as a result of duplications and differences occurred in mutations resulting in pseudogenes. $\mathrm{WC} 1^{+} \gamma \delta$ $\mathrm{T}$ cells in cattle have been shown to use TCR $\gamma$ genes from only one of the six available cassettes. The structure of that $\mathrm{C} \gamma$ gene product is unique and may be necessary to interact with WC1 for signal transduction following antigen ligation. Using RT-PCR and PacBio sequencing, we observed the same restriction for goat $\mathrm{WC}^{+} \gamma \delta \mathrm{T}$ cells. In contrast, caprine $\mathrm{WC}^{+}$ and $\mathrm{WC}^{-} \gamma \delta \mathrm{T}$ cell populations had a diverse TCR $\delta$ gene usage although the propensity for particular gene usage differed between the two cell populations. Noncanonical recombination signal sequences (RSS) largely correlated with restricted expression of TCR $\gamma$ and $\delta$ genes. Finally, caprine $\gamma \delta$ T cells were found to incorporate multiple TRD diversity gene sequences in a single transcript, an unusual feature among mammals but also previously observed in cattle.
\end{abstract}

Keywords Goat $\cdot \gamma \delta$ T cells $\cdot$ TCR $\cdot$ TRD $\cdot$ TRG $\cdot$ WC1

\section{Introduction}

Goats are an important component of agriculture in developing countries, serving as a source of food and other commodities. Therefore, the generation of immunity to pathogens to maintain animal health is pertinent to both human nutrition and economic stability. Ruminants as well as pigs and poultry have a large proportion of $\gamma \delta \mathrm{T}$ cells in their peripheral blood mononuclear cell (PBMC) populations, and thus, these species are considered " $\gamma \delta$ T cell high" (Hein and Mackay 1991; Mackay and Hein 1989; Sowder et al. 1988; Takamatsu et al. 2006; Yirsaw et al. 2021). In young cattle and sheep, up to $60 \%$ of PBMC can be $\gamma \delta$ T cells, supporting the notion that they are important for immunity early in life (Davis et al. 1996; Washington et al. 1992). It has been shown that caprine $\gamma \delta \mathrm{T}$ cells respond to various pathogens and in some cases are thought to contribute to protection (Yirsaw and Baldwin 2020). The $\mathrm{T}$ cell receptor (TCR) has been shown to be important for activating $\gamma \delta \mathrm{T}$ cell responses to pathogens in cattle (Baldwin et al. 2002; Blumerman et al. 2006; Lahmers et al. 2005; McGill et al. 2014), and thus,

5 Roslin Institute, University of Edinburgh, Edinburgh, Scotland, UK 
this is likely to be the same in goats. Although $\gamma$ and $\delta$ TCR genes are well characterized in cattle (Blumerman et al. 2006; Connelley et al. 2014; Conrad et al. 2007; Damani-Yokota et al. 2018; Herzig et al. 2010) and sheep (Piccinni et al. 2015; Vaccarelli et al. 2005), they have yet to be described in goats. Here, we sought to fill this gap.

The $\gamma \delta$ TCR is made up of two polypeptides, the $\gamma$ and $\delta$ chains, which are diversified by genomic rearrangement of genes that together constitute the variable region for antigen binding. In some species, the number of variable $(\mathrm{V})$ genes coding for these chains is many fewer than for the $\alpha$ and $\beta$ chains, and thus, there is a lower ability to generate diversity (Krangel 2009). However, in cattle, sheep, and pigs, an expanded repertoire of the TCR $\delta$ variable genes relative to that is humans and mice has been reported, with up to 60 TCR $\delta$ variable 1 (TRDV1) genes available for rearrangement (Antonacci et al. 2005; Piccinni et al. 2015; Uenishi et al. 2009). Also, a single TCR $\delta$ transcript in cattle has been shown to include sequence from all five diversity (D) genes generating long CDR3 regions (Herzig et al. 2010; Van Rhijn et al. 2007) while in mice and humans, only one or two TRDD gene sequences are incorporated. The TCR $\gamma$ gene loci in many species contain cassettes with one or several $\mathrm{V}$ and $\mathrm{J}$ genes and usually a single $\mathrm{C}$ gene in each (Conrad et al. 2007; Miccoli et al. 2003), although this does not occur in humans or poultry. Gene rearrangement within a cassette is favored (Blumerman et al. 2006). $\gamma \delta \mathrm{T}$ cells in cattle that express the lineage-specific hybrid pattern recognition receptor (PRR)/TCR co-receptor Workshop Cluster 1 (WC1) also only express TCR $\gamma$ genes from the TRGC5 cassette (Blumerman et al. 2006). As a result, the diversity of the $\gamma$ chain expressed by this subpopulation is limited to five $\mathrm{V}$ genes paired with the single $\mathrm{J}$ and $\mathrm{C}$ genes. We wished to determine if these peculiarities found in cattle also occur in goats.

The goat genome assembly ARS1 has an improved representation of the TCR loci relative to the previous reference genome, supporting investigation of genomic features of the $\gamma \delta$ TCR immune response. The ARS1 assembly employed an individual of the San Clemente goat breed that was highly homozygous (Bickhart et al. 2017). This is the most contiguous genome assembly for a non-model organism reported to date (Bickhart et al. 2017) made by combining longread PacBio single molecule real-time sequencing and physical mapping methods with error correction using shorter Illumina reads. Annotation of this assembly has already proven useful for other immune genes (Schwartz et al. 2018, 2019), so we sought to completely annotate the TCR $\gamma$ (TRG) and $\delta$ (TRD) loci and compare arrangement and usage of the variable genes with that in cattle. Goats and cattle diverged 30 million of years ago, and differences among polymorphic genes such as major histocompatibility complex (MHC) and leukocyte receptor complexes have evolved, although the two species share expansion of certain gene families (Schwartz et al. 2019). TCR genes do not display the same high levels of intra-species polymorphism and so may be more conserved on a genomic level across artiodactyl species. Thus, we hypothesized that the caprine TCR gene loci and structures will be similar to those of cattle and that $\mathrm{WC}^{+} \gamma \delta \mathrm{T}$ cells in goats will have the same restriction of TCR gene expression. We highlight many similarities of organization and expression of goat and cattle TCR genes but also key differences.

\section{Materials and methods}

\section{Genome annotation}

The long-read genome sequence assembly ARS1 from a San Clemente goat was retrieved from GenBank where it is deposited under BioProject accession code PRJNA290100 (Bickhart et al. 2017). The TRG genes were found on chromosome 4 (GenBank: NC_030811.1) and TRD genes on chromosome 10 (GenBank: NC_030817.1). Caprine TRG and TRD genes were annotated manually based on cattle TRG and TRD gene sequences (Blumerman et al. 2006; Conrad et al. 2007; Herzig et al. 2010; Ishiguro et al. 1993) that can be found in the IMGT database (www.imgt.org, last consulted May 2020), using the National Center for Biotechnology Information's (NCBI) Basic Local Alignment Search Tool (BLAST) after placing the bovine TRG and TRD sequences as query. The accession number for sequences used for bovine TRDC, TRDD, and TRDJ genes in the IMGT database is Btau_Chr10.28 whereas the accession number for sequences of TRDV genes are multiple, e.g., Btau_Chr10.28, Btau_un22, Btau_un41, Btau_un129, Btau_un139, etc. Similarly, the accession numbers of sequences used for bovine TRGC are D90409, D90411, D90414, X63680, AY735449, AY644518, and AY644517; for TRGJ are AY6445187, AY644518, AC172685, AY644517, 937068, and AC172685; and for TRGV are AY644517 and NW_937068. Computerbased annotation was done using Maker (Campbell 2014) and Apollo (Lewis et al. 2002) to verify the manually annotated TRG and TRD gene sequences as well as to search for additional exons coding for TCR genes. Maker Snap was trained multiple times to increase the accuracy and reliability of the predictions by inputting the annotated caprine TRG and TRD gene nucleotide and deduced amino acid sequences. The manual and the computer-based annotations were compared for gene exon locations and sequences. Pseudogenes were defined based on the presence of a truncation, nonsense mutation, frameshift, or defective initiation codon. Nomenclature of the annotated caprine TRG genes was based on similarity to the bovine gene sequence while TRD genes were named in order of occurrence on the chromosome. Recombination signaling sequences (RSS) were defined by locating 
the borders of each $\mathrm{V}, \mathrm{D}$, and $\mathrm{J}$ gene using expected canonical sequences and intervening spacing for these (Gellert 2002).

\section{Phylogenetic trees and alignments}

Trees comparing archived bovine TCR sequences with the identified caprine sequences were generated in two ways. First sequences were aligned in BioEdit (www.mbio.ncsu. edu/bioedit/bioedit.html, last accessed September 2020) with ClustalW then analyzed in an unrooted neighborjoining tree. Other trees were generated using Phylogeny.fr (www.phylogeny.fr, last accessed October 2020) (Dereeper et al. 2010, 2008) with sequences aligned with MUSCLE (www.ebi.ac.uk/Tools/msa/muscle/, last accessed September 2020).

\section{$\gamma \delta \mathrm{T}$ cell subpopulation purification}

Blood was collected from the jugular veins of Boer goats ranging from 2 to 3 years of age, housed at the University of Massachusetts' farm, as approved by the University of Massachusetts IACUC protocol \#2018-0081. PBMCs were isolated from blood by centrifugation over ficoll hypaque and cultured in complete RPMI medium (RPMI-1640 supplemented with $10 \%$ heat-inactivated fetal bovine serum (Hyclone), $200 \mathrm{mM}$ l-glutamine (Sigma), $5 \times 10^{-5} \mathrm{M} 2$-mercaptoethanol (Sigma), and $10 \mathrm{mg} / \mathrm{ml}$ gentamycin (Invitrogen)) with $5 \mu \mathrm{g} / \mathrm{ml}$ concanavalin A (ConA) for 2 days. Cells were stained with primary monoclonal antibodies $(\mathrm{mAb})$ GB21A (anti-TCRס) and CC15 (anti-WC1) purchased from Washington State University Monoclonal Antibody Center (Pullman, WA, USA) and then with secondary antibodies goat anti-mouse IgG2b-AF488 and IgG2a-AF647 (Invitrogen). Live lymphocytes were identified by forward and side scatter and were sorted using a FACS ARIA (Becton Dickinson) into $\mathrm{TCR} \delta^{+} / \mathrm{WC}^{+}$and $\mathrm{TCR} \delta^{+} / \mathrm{WC}^{-}$populations with $99 \%$ purity for both populations.

\section{RNA isolation and CDNA synthesis}

$\gamma \delta \mathrm{T}$ cells were solubilized in TRIzol (Invitrogen, Carlsbad, CA) and RNA extracted according to the manufacturer's instructions. RNA purity and concentration were determined by Nanodrop spectrophotometry (Thermo-Fisher). Reverse transcriptase was performed using Superscript IV (Invitrogen), a template switch oligo and a poly T reverse primer as outlined in Mamedov et al. (Mamedov et al. 2013). Primers, dNTPs and RNA were first incubated at $65^{\circ} \mathrm{C}$ for $5 \mathrm{~min}$, then enzyme, buffer, DTT, and RNase OUT (Invitrogen) were added before incubating at $50{ }^{\circ} \mathrm{C}$ for $1 \mathrm{~h}$ then $80^{\circ} \mathrm{C}$ for $10 \mathrm{~min}$. One unit of uracil deglycosylase (Invitrogen) was added per $20 \mu \mathrm{l}$ cDNA reaction and the mixture incubated at $37^{\circ} \mathrm{C}$ for $45 \mathrm{~min}$. For analysis of the TRDD usage, cDNA was made by using the AMV RT kit (Promega) and the oligo-dt primer.

\section{PCR and gene sequencing}

For TRDD expression, PCR used Taq polymerase (New England Biolabs) whereas PacBio sequence data was obtained from PCR products obtained using Phusion (NEB). Primers are outlined in Table 1. PCR was performed with the following conditions: (1) $95^{\circ} \mathrm{C}$ for $2 \mathrm{~min}$, (2) $95^{\circ} \mathrm{C}$ for $30 \mathrm{~s}$, (3) $55-63{ }^{\circ} \mathrm{C}$ for $45 \mathrm{~s}$, (4) $72{ }^{\circ} \mathrm{C}$ for $30 \mathrm{~s}$, repeating steps $2-4$ for 30 cycles. To confirm primer specificity or CDR3 sequences, amplicons were cloned into a sequencing vector by standard techniques and sent for commercial Sanger sequencing. For PacBio sequencing, PCR amplicons were loaded into a Sybersafe 1\% low melt agarose gel and following electrophoresis amplicons of the anticipated size $(\sim 500 \mathrm{bp})$ were extracted and purified with the Monarch gel extraction kit (NEB) and then purified further with Ampure beads (Beckman Coulter) and sequenced at the University of Massachusetts Medical School PacBio sequencing core (https://www. umassmed.edu/nemo/pacific-biosciences/). FastA files of

Table 1 Primers used for PCR

\begin{tabular}{ll}
\hline Primer Name & Sequence \\
\hline TRGC1 and 2 rev & GATTGTTTGACTGATGAAAGCGGTGCC \\
TRGC2 rev & CAAAGGCACGTCTGGAAGGTGAAAA \\
TRGC3 rev & GACATGCTTTTGTAGAATTTGCAACAGGGAC \\
TRGC4 rev & GGCTCCCAGTGACTGTTTAAACCAG \\
TRGC5 rev & GAGGTTGCTACACGTGCCTGCATG \\
TRGC6 rev & CTTGTTGACTTCTAGAAGATTCACCTCTTG \\
TRDC rev & ATATTGACCAAGCTTGACAGC \\
Universal fw & AAGCAGTGGTATCAACGCAGAGT \\
Universal fw pb01 & TCAGACGATGCGTCATCAAGCAGTGGTATCAACGCAGAGT \\
Universal fw pb02 & CTATACATGACTCTGCCAAGCAGTGGTATCAACGCAGAGT \\
Universal fw pb03 & TACTAGAGTAGCACTCCAAGCAGTGGTATCAACGCAGAGT \\
\hline
\end{tabular}

$f w$ forward primer, rev reverse primer, $p b$ PacBio tag 
sequences were analyzed by filtering sequences based on PacBio tags applied to different input populations during PCR. Sequences were then aligned as described above. Any repeated base pairs that likely occurred due to the PacBio sequencing errors were resolved based on comparison with known sequences of TCR. Frequency of recombination of TRGV genes with TRGC genes for transcription was presented as alluvial plots (open source application https://app. rawgraphs.io/; last accessed November 2020).

\section{Results}

\section{Chromosomal organization of caprine $\gamma \delta$ TCR genes}

Variable genes at the TRG and TRD loci were annotated using the most recent caprine reference genome assembly (Bickhart et al. 2017). Caprine TRG genes were identified at two loci (TRG1 and TRG2) on chromosome 4 as previously reported (Antonacci et al. 2007) while a single TRD locus was located on chromosome 10. The TCR $\gamma$ $\mathrm{V}, \mathrm{D}, \mathrm{J}$, and $\mathrm{C}$ genes identified were named according to their closest homology with bovine genes, while the TCR $\delta$ genes were named in order as they were found on the chromosome.

a
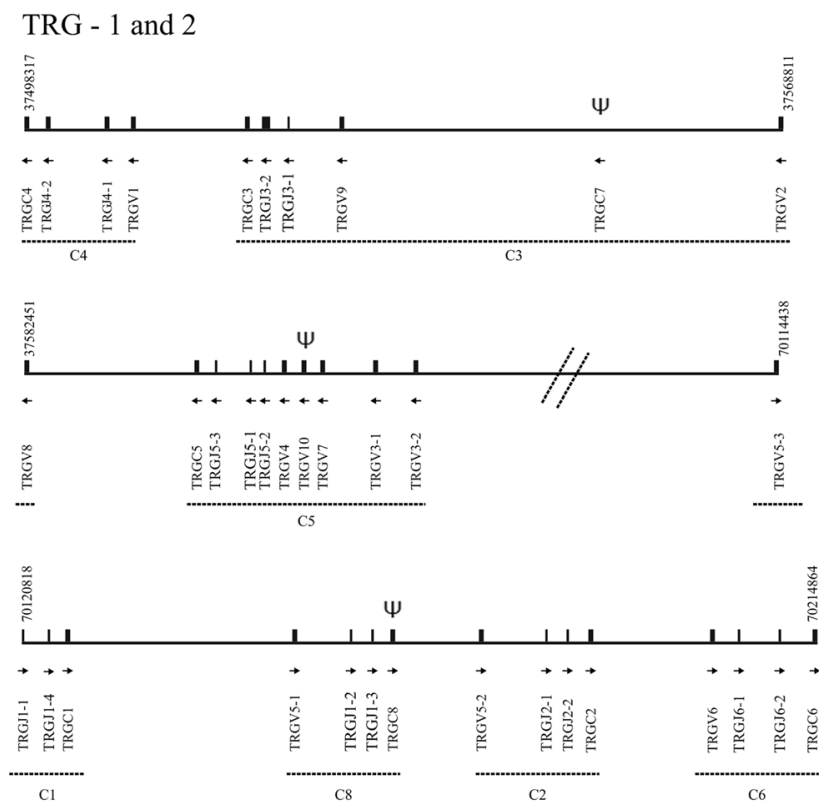

Fig. 1 Organization of the caprine TCR loci. Arrows indicate the orientation of the genes. a The TRG genes found at two loci on chromosome 4 separated by a double slash. The TRG1 locus was found between position $37,498,317$ and $37,637,483$ whereas the TRG2 locus was located between position $70,114,164$ and $70,214,864$.
The TRG1 locus lies on the centromeric side of the TRG2 locus on chromosome 4 with the three observed cassettes transcribed in a telomeric to centromeric orientation (Fig. 1a). These 3 cassettes were named C4, C3, and $\mathrm{C} 5$ in the order they are located from centromeric to telomeric; both $\mathrm{C} 3$ and $\mathrm{C} 5$ cassettes had multiple V and $\mathrm{J}$ genes. The $\mathrm{C} 3$ cassette also had an additional constant gene, TRGC7, located between TRGV9 and TRGV2 and was classified as a pseudogene due to a frame shift. The TRG2 locus lies on the telomeric side of TRG1 and the four cassettes identified are transcribed in a centromeric to telomeric orientation (opposite to that of TRG1). Most caprine TRGV genes found were predicted to be functional except for TRGV10 that had a point mutation that induces a stop codon (Fig. S1b).

The TRD locus had 36 TRDV genes, 7 TRDD genes, 4 TRDJ genes, and 1 TRDC gene (Fig. 1b). The TRDV1 family expansion in goat was composed of 30 genes. The 36 TRDV genes alternated orientation, with 11 TRDV1 genes in opposite orientation to all of the TRDD and TRDJ genes, and the TRDC gene. In addition, TRDV5 is in an inverted orientation and positioned after the TRDC gene, as it is in other mammals. b

TRD GENE
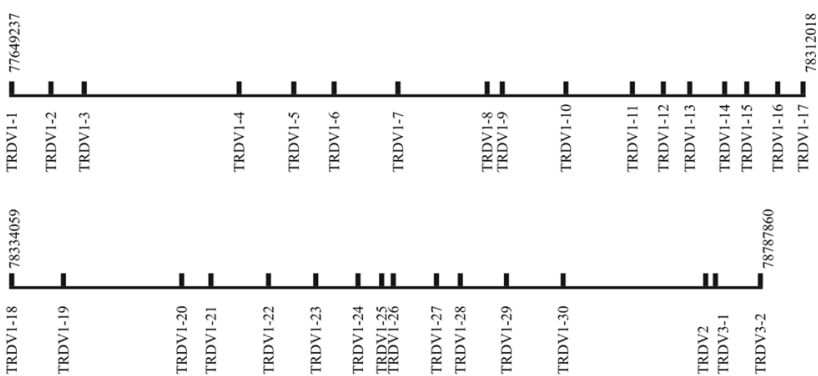

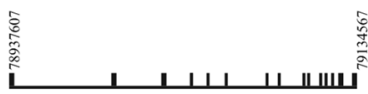

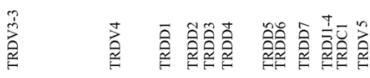

Genes were named based on homologous genes in cattle. Dotted underlines represent predicted cassettes within which gene rearrangements would occur. b The TRD genes are located on chromosome 10 between 77,649,737 and 79,134,567. The genes were named in order as found on the chromosome 
Fig. 2 Phylogenetic analysis of caprine and bovine TRGV and TRGC genes. Annotated sequences from goats and bovine nucleotide sequences from IMGT were aligned with MUSCLE and displayed in an unrooted maximum likelihood phylogenetic tree. a TRGV and b TRGC. Numbers on branches indicate support values. "c" before a gene name indicates a caprine TCR sequence and " $b$ " before a gene name indicates a bovine TCR sequence a

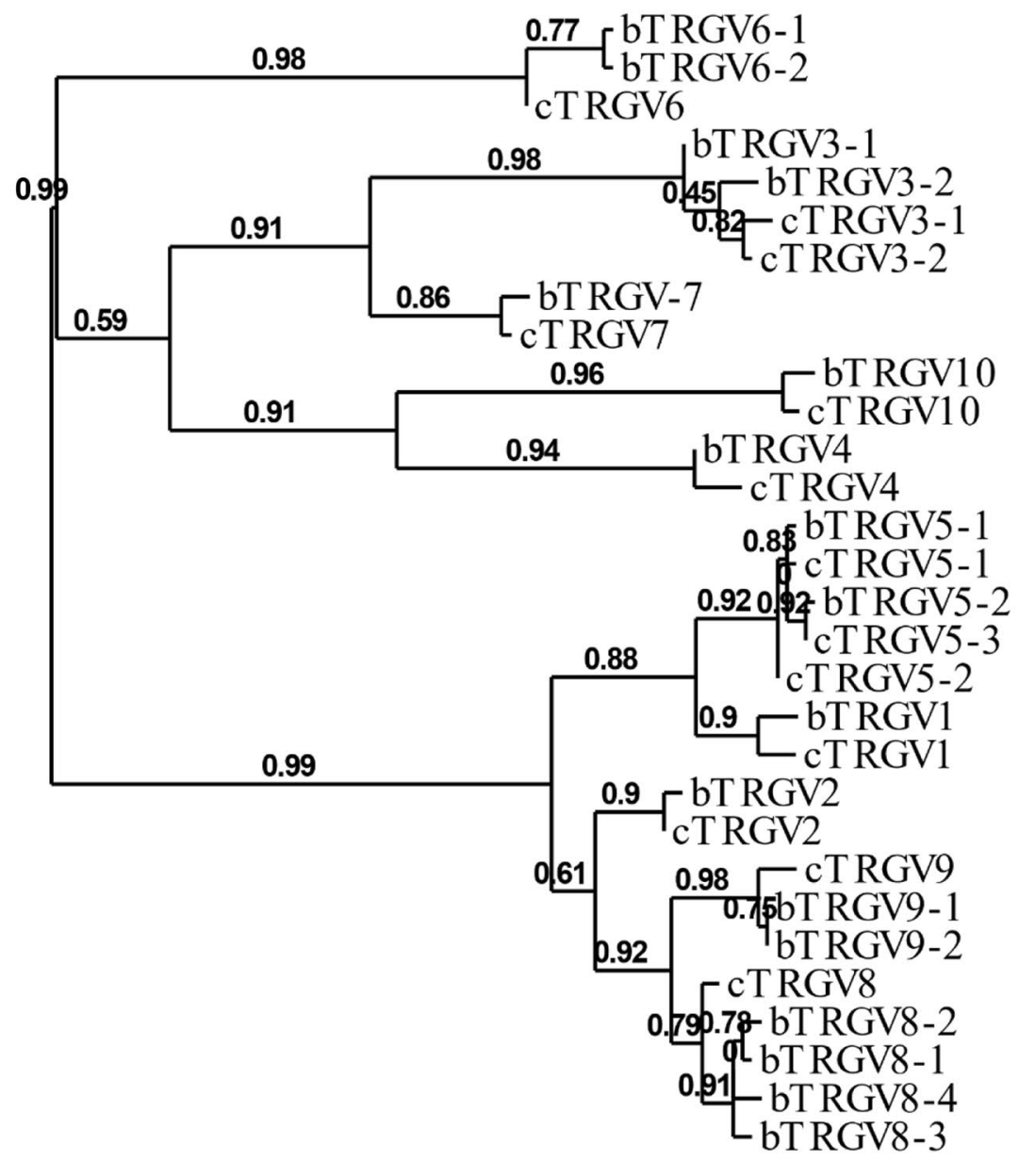

0.2

b

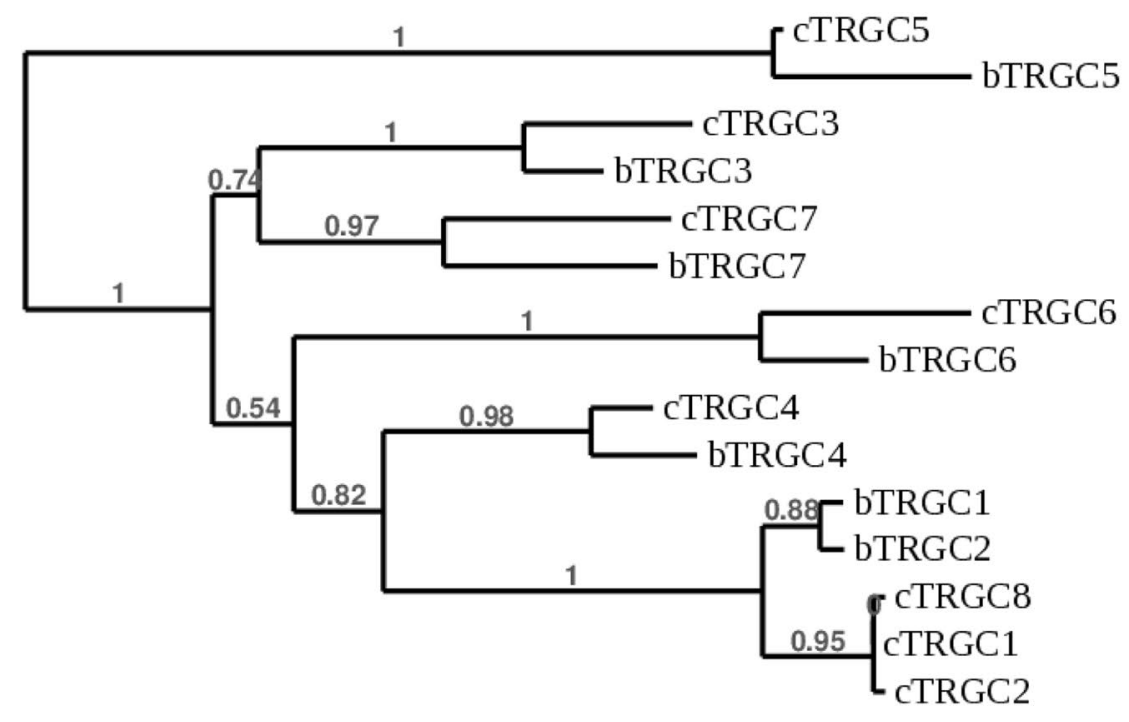

0.08 
Fig. 3 Phylogenetic comparison of caprine and bovine TRDV genes. TRDV genes were aligned with ClustalW using default parameters and displayed in a neighbor-joining phylogenetic tree. A "c" before a gene name indicates a caprine TCR sequence and "b" indicates a bovine TCR sequence. Bovine sequences followed naming conventions from previous annotations. Lines indicate subclades assigned by a clustering of two nodes of difference and $\geq 87 \%$ identity among the sequences in a subclade

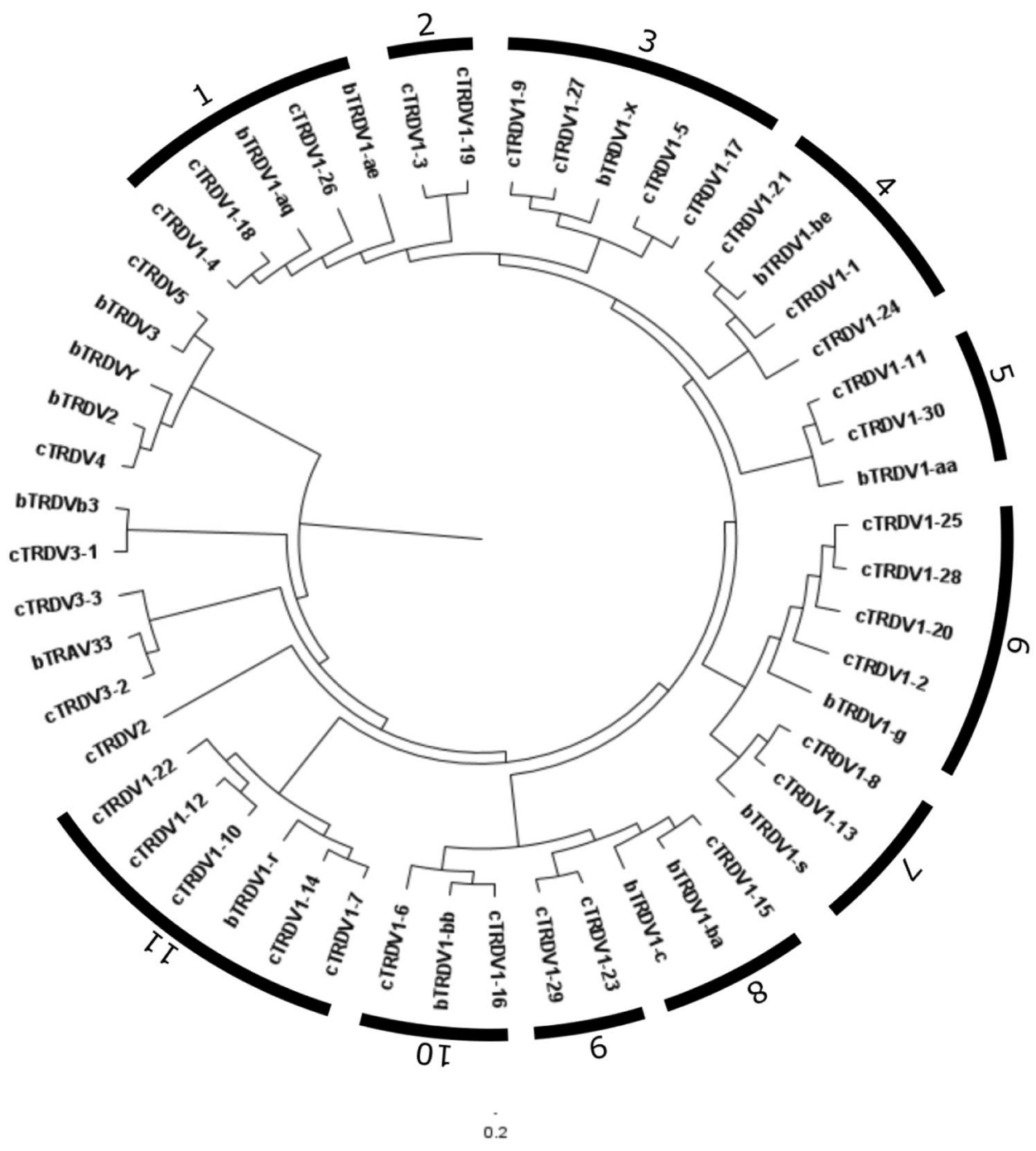

\section{Comparison of caprine and bovine TCR gene organization and sequences}

The order of the caprine TRG cassettes and the contents of each were largely similar to those in cattle (Fig. S1a) although cattle only have six TRG cassettes (missing TRGC 8 cassette) and the bovine TRG1 locus is in a forward orientation. Although a bovine homologue of TRGC7 is not reported in the literature, sequence for a homologous pseudogene is found in the IMGT database and a locus map that has been published (Antonacci et al. 2007) shows that it is in a similar position as we found TRGC7 in goats. Finally, TRGV10 was not found to be a functional gene in goats but it is in cattle.

With regard to the TRD locus, the genes were also organized similarly to those in cattle implying that the TRD genes may have functional equivalence. However, while goats had more TRDD genes and an additional TRDJ gene, we were unable to find a caprine homologue for bovine TRDVy
(Connelley et al. 2014; Damani-Yokota et al. 2018) and the number of TRDV1 genes in goats was also less than the over 50 TRDV1 bovine genes (Antonacci et al. 2005; Herzig et al. 2010).

The conservation of TCR $\gamma$ loci organization between cattle and goats suggested that the respective caprine and bovine TRGV, TRGJ, and TRGC genes would cluster based on gene name and locus location in a phylogeny analysis. When aligned (Fig. S2a) and analyzed, all TRGV genes corresponded to a bovine gene in a maximum likelihood tree except that there was no caprine homologue of bovine TRGV11, a pseudogene found in both cattle and sheep (Fig. S2a). There was also more duplication of certain TRGV genes of goats compared to that is cattle such as the TRGV5 gene. In most instances duplicated genes clustered more closely within a species than between species which could be due to duplication events occurring post-species divergence (Fig. 2a). TRGC gene sequences (Fig. S2b) clustered between species in 
Fig. 4 Alignment of caprine and bovine joining and diversity gene sequences. Nucleotide lineups of caprine and bovine sequences by ClustalW using default parameters a TRGJ, b TRDJ, and c TRDD; dashes indicate gaps put in place to improve alignment. Dots represent the same nucleotide as that shown in the first reference sequence a

CTRGJ1-1
bTRGJ1-1
CTRGJ1-2
CTRGJ1-3
bTRGJ1-2
CTRGJ1-4
CTRGJ2-1
bTRGJ2-1
CTRGJ2-2
bTRGJ2-2
CTRGJ3-1
bTRGJ3-1
CTRGJ3-2
CTRGJ4-1
bTRGJ4-1
CTRGJ4-2
bTRGJ4-2
CTRGJ5-1
bTRGJ5-1
CTRGJ5-2
CTRGJ5-3
CTRGJ6-1
CTRGJ6-2
bTRGJ6-1

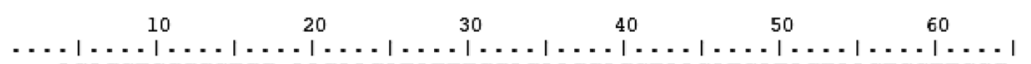
-ACAGCTCGGGTGG-AAGAAGATATTTGGAGAAGGAGCTAACATCATAGTAACTCGTTGGG-

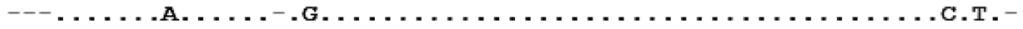

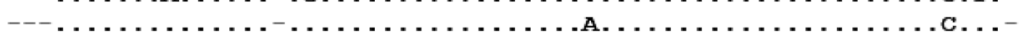
--- GAATAA. TACTTA. .A.AC. . CAA. . TT. . . .A. .AC. . . T. . . .AG---

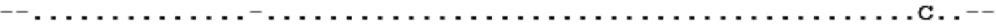

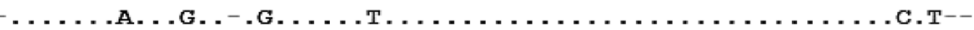
. TAATAA. TAC. TA. .A.AC. . СAAT . TT . . . . . A. .AC. . . T. . . . .AG---

----GAATAG. TACTTA. .A.AC. . СAAT. TT. . . . A. .AC. . . T. . . . AG--------T. .TG.A......................G.GC........T.CC.T--

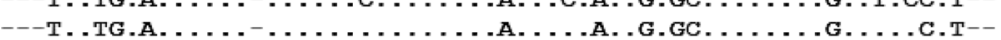
ga - - - AATAA. TAC. .A. .A.AC. . СAAT . TT . . A.A. .AC. TG. T . . . . AG------

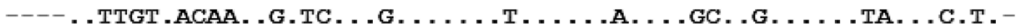
--...T. .AAC...-.TC...G..............GC..G.....TA....T.CAA. . . G.G.CCAGA.C.TC. .AG.G. . . TTCCA. .A.AC.AC.T. . . . T. .AG-CAA.

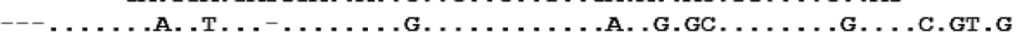
---

b

\begin{tabular}{|c|c|}
\hline TRDJ1 1 & \\
\hline bTRDJ1 & --- A. GAGAC.G. . \\
\hline RRDJ2 & GCTCC.GGGACACC \\
\hline bTRDJ2 & - CAG. . \\
\hline CTRDJ3 & -- CAGA. T \\
\hline TRDJ3 & -СTCC. GGGACACC \\
\hline 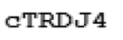 & \\
\hline & $\begin{array}{c}10 \\
.1\end{array}$ \\
\hline CTRDD1 & АTTGG-TTGGA \\
\hline bTRDD1 & G. . .AC . .G.GG \\
\hline CTRDD2 & GG . . . GA. TT . CGA \\
\hline bTRDD2 & GG . . . GA . TT . CGA \\
\hline CTRDD3 & -АСТАСA.AT . C- \\
\hline bTRDD3 & GG. . .GG.ACTA. \\
\hline CTRDD 4 & GCG. . AG . ACTCG \\
\hline bTRDD 4 & $-\mathrm{ACAACG} . \mathrm{AC}---$ \\
\hline cTRDD5 & GG . . .GG . ACTA. \\
\hline bTRDD5 & GG. . . GA . ACG-- \\
\hline CTRDD6 & -A. TACG . AC-- \\
\hline TRDD7 & $. \mathrm{GA} \cdot \mathrm{AC} .-$ \\
\hline
\end{tabular}

an expected way (Fig. 2b). Since there is not a bovine equivalent of caprine TRGC8, this gene clustered with its neighboring TRGCs, i.e., TRGC1 and TRGC2. This may indicate that this is a duplication that occurred within the caprine cassette given the similar organization and homology of the other $\mathrm{V}$ and $\mathrm{J}$ genes found there and that this event did not occur in cattle. The caprine pseudogene TRGC7 clustered with the other $\mathrm{C}$ gene in that cassette, i.e., TRGC3, indicating that this too may be a duplication event.

TRDV genes among ruminant species were aligned with representative bovine TRDV1 genes (Fig. S2c) from each of the 11 TRDV1 subfamily groups described previously, along with the other TRDV genes (Damani-Yokota et al. 2018; Herzig et al. 2010) and bovine
TRAV33. TRAV33 was classified as a TRAV based on homology with human TRAV genes but has been shown to rearrange with TRDC (Connelley et al. 2014). It was included as a benchmark. A neighbor-joining tree of caprine TRDV1 genes showed that they clustered into 11 subclades (Fig. 3), although not all of them clustered with representative bovine TRDV 1 genes. There were 2 subclades (2 and 9) of caprine TRDV1 genes that did not contain a bovine TRDV1 gene and two subclades that contained two bovine TRDV1 genes (subclades 1 and 8). Since the 11 genes from the different subclades of bovine TRDV1 genes may not have been the best representatives of the groups in cattle, we also evaluated all the bovine TRDV1 genes with the caprine genes in a phylogenetic tree (Fig. S3). This analysis showed 13 different bovine 
Fig. 5 PCR of $\gamma \delta$ T cell subpopulations. a Flow cytometry cell sorting strategy for caprine PBMCs that were first gated on live lymphocytes based on forward (fsc) and side scatter (ssc). Cells were stained by indirect immunofluorescence using $\mathrm{mAbs}$ reactive with $\mathrm{WC} 1$ or TCR $\delta$. Numbers displayed indicate percentage of cells within regions. Background responses with secondary Abs only were $0.2 \%$ with AF488 and $1.8 \%$ with AF647. b Gel electrophoresis of RT-PCR products using sorted cell populations as templates with the indicated primers a

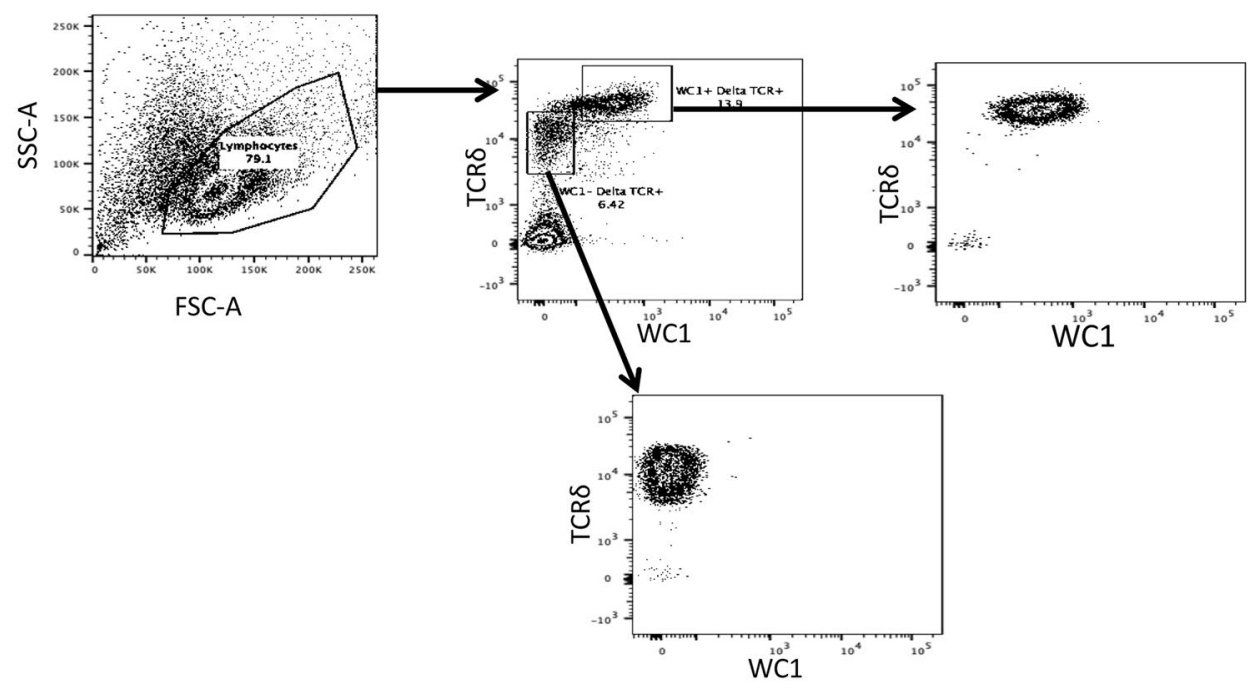

b

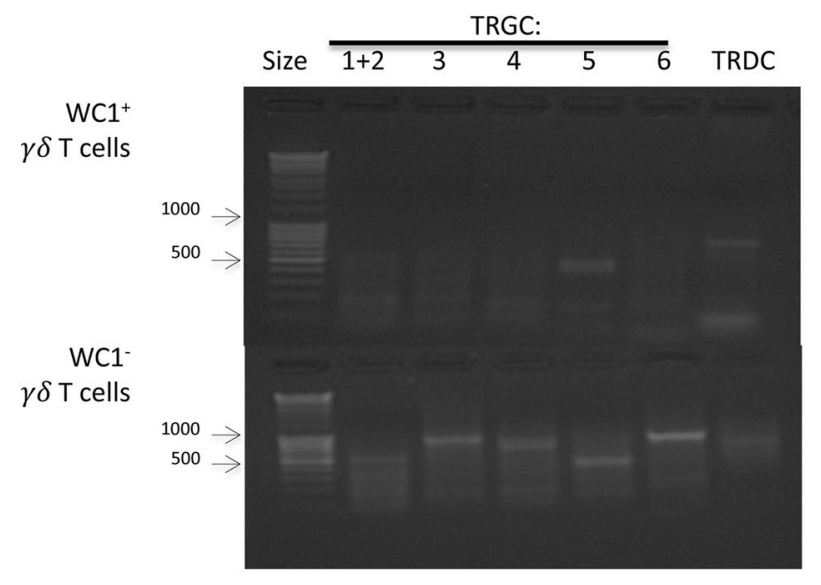

analogous (Fig. 4a, b). Although goats had more TRG cassettes than cattle, as noted above, both species have approximately the same number of TRGJ genes, some of which appear to have resulted from distinct duplication events (Fig. 4a). For example, goats have unique duplications of TRGJ1 (TRGJ1-2) and TRGJ3 (TRGJ3-2). In contrast, some TRDD genes that have a similar location in both species displayed lower sequence conservation (Fig. 4c). It is difficult to assess the impact of this TRDD diversity due to the very short sequences of these genes that are also subject to $\mathrm{N}$ and $\mathrm{P}$ addition during recombination.

\section{TCR gene expression among $\gamma \delta \mathrm{T}$ cell subpopulations}

The conservation of TCR $\gamma$ and $\delta$ genes between goats and cattle suggests that they may share similar expression patterns among $\gamma \delta \mathrm{T}$ cell subpopulations. We addressed the hypothesis that $\gamma \delta \mathrm{T}$ cells expressing $\mathrm{WC} 1$ will have a 
Table 2 Transcription of TRG genes by the $\mathrm{WC1}^{+}$and $\mathrm{WC1}^{-} \gamma \delta \mathrm{T}$ cells

\begin{tabular}{|c|c|c|c|}
\hline $\begin{array}{l}\text { TRGC cassette that the } \\
\mathrm{V} \gamma \text { gene is associated }\end{array}$ & TCR V $\gamma$ gene name & $\begin{array}{l}\mathrm{WC}^{+} \gamma \delta \\
\mathrm{T} \text { cells }\end{array}$ & $\begin{array}{l}\mathrm{WC1}^{-} \\
\gamma \delta \mathrm{T} \\
\text { cells }\end{array}$ \\
\hline TRGC 1 & TRGV5-3 & - & + \\
\hline \multirow[t]{2}{*}{ TRGC 2} & TRGV 5-1 & - & + \\
\hline & TRGV 5-2 & - & + \\
\hline \multirow[t]{4}{*}{ TRGC 3} & TRGV 2 & - & + \\
\hline & TRGV 8-1 & - & + \\
\hline & TRGV 8-2 & - & + \\
\hline & TRGV 9 & - & + \\
\hline TRGC4 & TRGV 1 & - & + \\
\hline \multirow[t]{5}{*}{ TRGC5 } & TRGV3-1 & + & + \\
\hline & TRGV3-2 & - & - \\
\hline & TRGV4 & - & - \\
\hline & TRGV7 & + & + \\
\hline & TRGV10 & - & - \\
\hline TRGC6 & TRGV6 & - & + \\
\hline
\end{tabular}

Following flow cytometric purification of $\gamma \delta \mathrm{T}$ cell populations, RTPCR and PacBio sequencing was used to assess gene transcription. +, gene transcribed

restricted expression of TRG genes, using only those found in the TRGC5 cassette as occurs in cattle (Blumerman et al. 2006). Amino acid identity between cattle and goat gene sequences in the TRGC5 cassette was $\geq 87 \%$ (TRGJ5, 87\%; TRGV4, 91\%; TRGV7, 92\%; TRGV3, 94\%; TRGV10, 95\%; and TRGC5, 96\%) attesting to their similarity (see Fig. S1b). PCR was performed with cDNA made from flow-cytometrically sorted $\mathrm{WC}^{+} / \mathrm{TCR}^{+}$and $\mathrm{WC}^{-} / \mathrm{TCR}^{+}$cells (Fig. $5 \mathrm{a}$ ). $\mathrm{WC1}^{+}$cells had no product except for TRGC5 whereas $\mathrm{WC}^{-} \gamma \delta \mathrm{T}$ cells transcripts for all TRGC genes evaluated (Fig. 5b). This indicated that caprine $\mathrm{WC}^{+}$cells share the same restricted TRG gene usage as observed in cattle. To confirm these sequences, PCR amplicons were sent for PacBio sequencing. TRGV3-1 and TRGV7 were largely the only TRGV genes found among the $\mathrm{WC}^{+}$population's transcripts aside from 2 transcripts of TRGV9 and TRGV6 (that is likely a result of contamination during flow cytometry sorting) whereas the $\mathrm{WC1}^{-}$population used all available TRGV genes except for TRGV4, TRGV3-2, and TRGV10 (Table 2 and Fig. 6a). TRGV10 is predicted to be a pseudogene due to a stop codon found within the gene, whereas TRGV4 and TRGV3-2 are predicted to be functional and are in open reading frame. The data also confirmed that expression of TCR $\gamma$ genes is indeed limited to rearrangement within cassettes (Fig. 6b).
We also addressed TRD gene usage. Unlike what we found for the TRG genes, the $\mathrm{WC}^{+}$and $\mathrm{WC}^{-} \gamma \delta \mathrm{T}$ cell populations both had distinct, highly diverse repertoires of TRDV gene transcription (Table 3 and Fig. 6) with genes from all 11 clades of TRDV1 transcribed by both subpopulations. We did find some differences among the subpopulations, e.g., $\mathrm{WC1}^{-}$cells had more transcripts for TRDV3-2 than the $\mathrm{WC}^{+}$population did. We also found that multiple TRDD genes were incorporated into the transcripts as occurs in cattle (Herzig et al. 2010, 2015; Van Rhijn et al. 2007). Here, by RT-PCR and Sanger sequencing, we found that as many as three TRDD genes were incorporated (Fig. 7).

\section{RSS sequences}

The conservation of the caprine TCR gene structures with that of other mammals was evaluated by identification of RSS (Chen et al. 2009; Parra et al. 2008; Yang et al. 2017). A change in gene expression can occur if the heptamer and nanomer are noncanonical, e.g., either a noncanonical or a mutated RSS have specifically been shown to reduce expression of caprine immunoglobulin J genes (Schwartz et al. 2018). The RSS of most of the caprine TRDV and TRDD genes adhered to the canonical motifs observed in other species with a CAC at the start of the heptamer and a homopolymer in the nonamer (Table S1). Three of the TRGV genes deviated from the conserved heptamer sequence and four of the 13 total genes had different nonamers (Table S2). We also examined the RSS of the TRDD, TRDJ, and TRGJ genes. The distal end of the heptamer is shown in Table S3 and is where the reverse complement of the canonical sequence occurs (...GTG). We found this varied among these genes. While most of the genes had a conserved thymidine at nt 5 in the RSS, six genes had some variation there as well (Table S3).

When transcripts of TRGV and TRDV genes with noncononical RSS sequences were evaluated, we did not find transcripts for $70 \%$ of those genes in the transcript pool of either $\mathrm{WC}^{+}$or $\mathrm{WC}^{-}$populations. When observing transcription of TRGV genes with noncanonical RSS, we found that TRGV6, TRGV7, and TRGV3-1 were still transcribed and therefore still underwent gene rearrangement. However, transcripts for TRGV4 and TRGV10 that also have noncanonical RSS were not found. None of the TRDV genes with noncanonical RSS were found to rearrange. The absence of transcripts may indicate that rearrangement did not occur due to the noncanonical RSS or that the PacBio sequencing pool was not deep enough to identify transcript for those genes. 
Fig. 6 TRDV and TRGV gene usage. a PacBio sequencing of TCR genes from $\mathrm{WC}^{+}$and $\mathrm{WC}^{-} / \mathrm{TCR}^{+}$cells sorted by flow cytometry. Percentage of transcripts from each gene was obtained by dividing the number of transcripts by the total transcripts that appeared as "hits" against a database of TRGV, TRGC, or TRDV genes obtained from this annotation. b Alluvial plots showing TRGV and TRGC gene combinations used in transcripts a

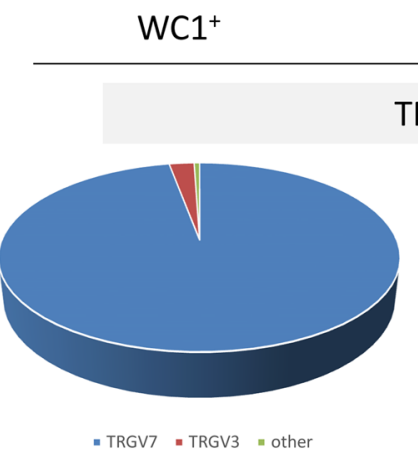

TRG

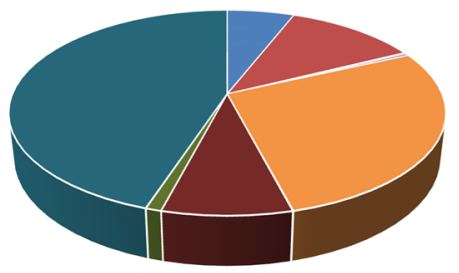

$$
\begin{array}{ll}
\text { - TRGV1 = TRGV2 } & \text { = TRGV5-1 = TRGV5-2 } \\
\text { - TRGV5-3 = TRGV6 } & \text { - TRGV8-1 - TRGV8-2 } \\
\text { - TRGV9 = TRGV3 } & \text { - TRGV7 }
\end{array}
$$

No other TRGC RT-PCR products were obtained for sequencing other than TRGC5.

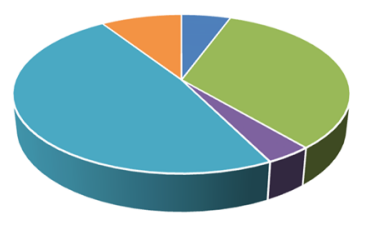

- TRGC1 - TRGC2 - TRGC3 - TRGC4 = TRGC5 = TRGC6

TRD
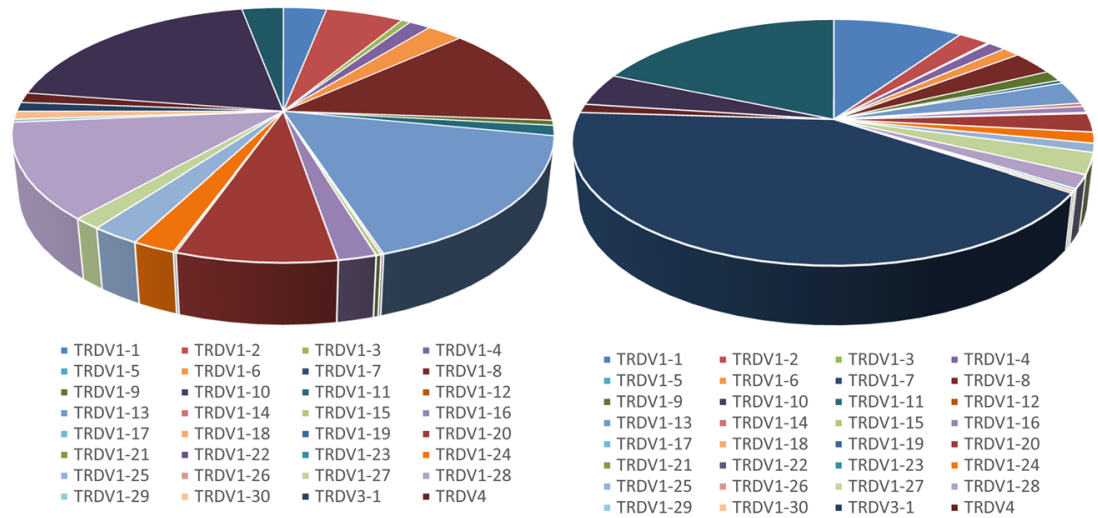

- TRDV1-1 " "TRDV1-2 " "TRDV1-3 = TRDV1-4 - TRDV1-5 "TRDV1-6 - TRDV1-7 = TRDV1-8 - TRDV1-9 - TRDV1-10 "TRDV1-11 "TRDV1-12

- TRDV1-13 "TRDV1-14 "TRDV1-15 "TRDV1-16

-TRDV1-17 "TRDV1-18 - TRDV1-19 "TRDV1-20

-TRDV1-21 "TRDV1-22 "TRDV1-23 "TRDV1-24

TRDV1-25 "TRDV1-26 "TRDV1-27 = TRDV1-28

TRDV1-29 = TRDV1-30 - TRDV3-1 - TRDV4

TRDV2 - TRDV3-2 - TRDV5

b

BorTRGV3-1
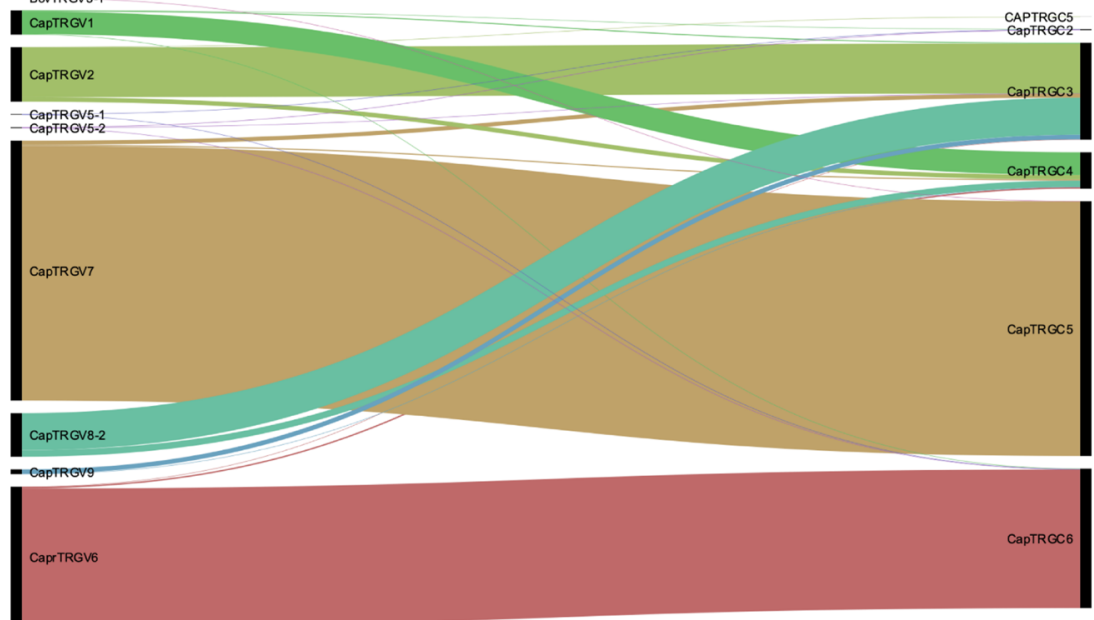
Table 3 Transcribed TRDV1 genes by $\gamma \delta$ T cell subpopulations

\begin{tabular}{llc}
\hline TCR6 V genes & $\mathrm{WC1}^{+} \gamma \delta \mathrm{T}$ cells & $\mathrm{WC1} 1^{-}$ \\
& & $\gamma \delta \mathrm{T}$ \\
& & cells \\
\hline TRDV1 subclade 1 & + & + \\
TRDV1 subclade 2 & + & + \\
TRDV1 subclade 3 & + & + \\
TRDV1 subclade 4 & + & + \\
TRDV1 subclade 5 & + & + \\
TRDV1 subclade 6 & + & + \\
TRDV1 subclade 7 & + & + \\
TRDV1 subclade 8 & + & + \\
TRDV1 subclade 9 & + & + \\
TRDV1 subclade 10 & + & + \\
TRDV1 subclade 11 & + & + \\
TRDV2 & - & - \\
TRDV3-1 & + & + \\
TRDV3-2 & + & + \\
TRDV3-3 & - & - \\
TRDV4 & + & - \\
TRDV5 & + & + \\
\hline
\end{tabular}

Following flow cytometric sorting of $\gamma \delta \mathrm{T}$ cell populations, RT-PCR and PacBio sequencing was used to assess gene transcription. + , gene transcribed

\section{Discussion}

Our work with the caprine $\gamma \delta$ TCR genes continues to fill gaps in our knowledge regarding the evolution of the $\gamma \delta$ TCR among artiodactyls and, more specifically, among ruminant species. Moreover, while cattle and goats diverged evolutionarily several million years ago, our data indicates that they share a high degree of similarity in the organization of their TRG and TRD genome loci and gene sequences within those loci, as well as gene transcription patterns by $\gamma \delta \mathrm{T}$ cell subpopulations. The large number of duplication events in both the TRG and TRD loci that are analogous in the bovine and caprine genomes is striking. Overall, this work continues to support the evidence that the $\gamma \delta$ TCR gene repertoire diversity is much greater in ruminants compared to humans and mice, mirroring the expansion of $\gamma \delta \mathrm{T}$ cells in the blood of ruminants.

A striking feature of the TRD locus for more than one species of artiodactyls is the expanded TRDV1 repertoire compared to that of humans and mice (Antonacci et al. 2005; Yang et al. 1995). The 30 caprine TRDV1 genes identified also indicates an expansion although less than for cattle with their more than 60 genes or sheep with their 40 genes. There is the possibility that more caprine TRDV1 genes are located upstream within the TRA locus although we found no evidence for that in the ARS1 assembly. Previous phylogenetic analysis by others showed that 35 of the 40 sheep TRDV 1 genes cluster into 5 groups (Antonacci et al. 2005; Piccinni et al. 2015) while using our criteria, we have shown that both bovine and caprine TRDV1 genes segregated into 11 phylogenetic groups or subclades (Herzig et al. 2010). Only the bovine subclade represented by TRDV1-c was excluded from clustering with caprine genes. Although goats have fewer TRDV1 genes than cattle, diversity of their TCR may occur by virtue of having more TRDD and TRDJ genes available for rearrangement than cattle here.

While the organization of the caprine TRG loci was similar to those in cattle and sheep, there were some unique aspects. Most of the differences found among ruminant species evaluated here appear to be due to duplication events through evolution. In addition, the caprine TRG1 locus was in an inverted orientation relative to that in cattle (Antonacci et al. 2020b; Conrad et al. 2007), although this could be an assembly error. An additional nonfunctional caprine TRG gene, TRGC8, was found that is not in sheep or cattle. Caprine TRGC7 does not have an ovine homologue while in cattle it is also a pseudogene (IMGT www.imgt.org). Based on their location and homology to neighboring TRGC genes we assume that these pseudogenes are duplications of functional $\mathrm{C}$ genes in both goats and cattle. During the course of this work, a publication became available very recently that included annotation of the caprine TRG loci and made comparisons to sheep pointing out similarities and differences as we have done here for goats and cattle (Giannico et al. 2020).

The number of genes available during recombination is clearly related to the diversity of the final repertoire of antigen-binding potentials. However, not all of the genes appear to be equally used. Control of usage through the RSS may substantially impact the representation of each gene in the repertoire. Canonical RSS sequences are expected to influence the ability of RAG-mediated rearrangement to occur (Wei and Lieber 1993). That is, genes found without the canonical heptamer sequence will not be rearranged or will be rearranged at a lower frequency than genes that have it. The influence of the RSS of TCR and immunoglobulin genes have been characterized in a range of species from sandbar sharks to opossums (Chen et al. 2009; Hassanin et al. 2000; Parra et al. 2008; Yang et al. 2017) including for caprine immunoglobulin genes, i.e., noncanonical or mutated RSS resulted in less expression of the particular J genes (Schwartz et al. 2018). In agreement with mice and human, caprine TCR genes are also flagged in the same way with the same canonical starting sequence of CAC within the heptamer. Very few genes had a noncanonical sequence. Overall, the caprine TCR genes of both TRD and TRG loci followed 
Fig. 7 Multiple TRDD gene usage. CDR3 nucleotide sequences and their corresponding deduced amino acid sequences were aligned below the germline sequences to demonstrate TRDD usage. TRDD genes are shaded and gene usage was determined by the presence of at least five nucleotides of a particular TRDD gene. Sufficient cDNA sequence was analyzed to determine TRDV gene usage although the complete sequences of TRDV and TRDJ genes are not shown

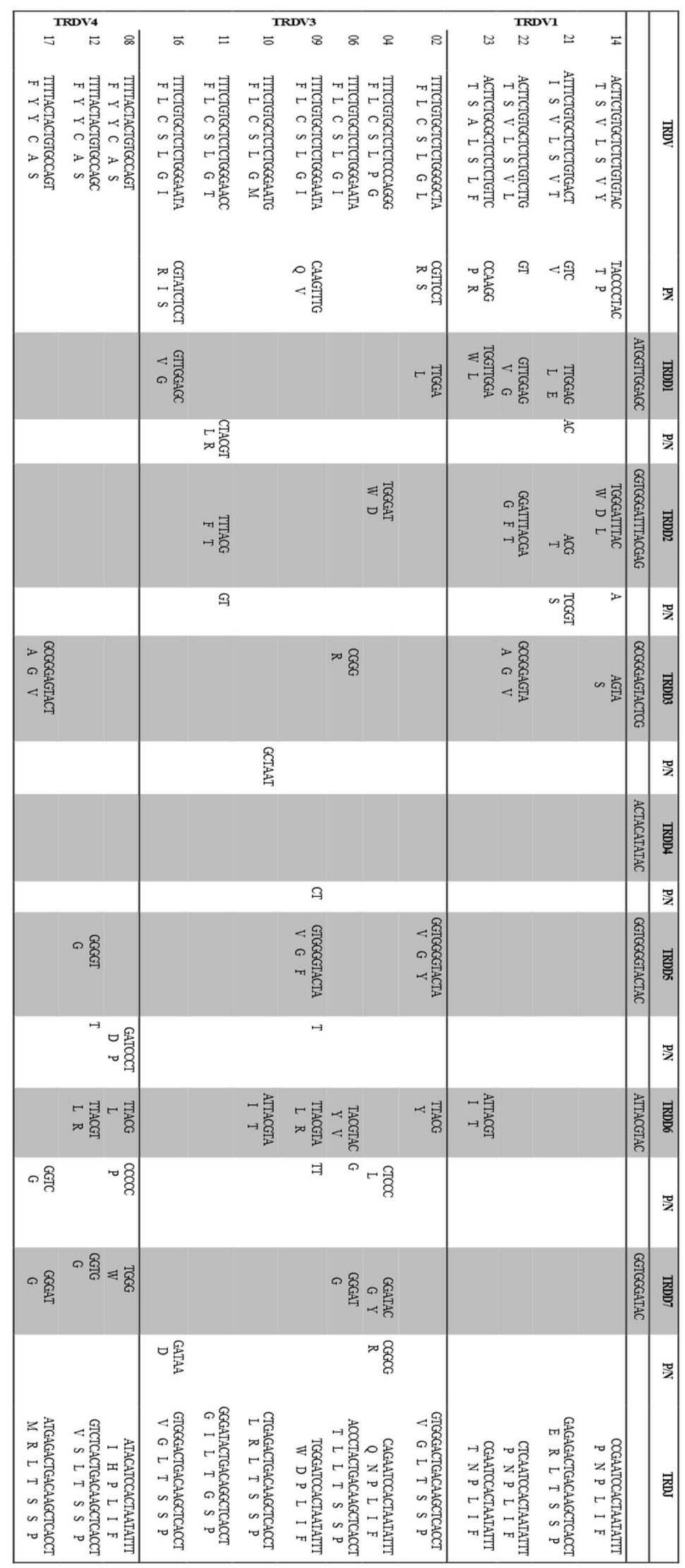


the same RSS conventions in canonical sequence within the nanomer and heptamer as those for other species, with few caprine TCR genes having changes within the conserved regions. Of the few $\mathrm{V}$ genes with noncanonical RSS sequences many could not be found in the transcript pool indicating they may not be expressed or expressed in low amounts. The conservation of RSS sequences among caprine TRDV1 genes supports the idea that these genes underwent large-scale duplication events during evolution.

Depending on the antigen, the $\gamma \delta$ TCR may use one of the two chains' more predominantly to interact. For example, the TCR $\delta$ CDR3 has been shown by crystal structures to be the dominant chain used in mouse $\gamma \delta$ $\mathrm{T}$ cell interactions with MHC like molecules such as T22 and CD1d (Adams et al. 2005; Luoma et al. 2013) while the TCR $\gamma$ chain variable gene product has been shown to be important for interaction with butyrophilinlike molecules (Willcox et al. 2019). But, generally the CDR3 is the component of the TCR chain that interacts with antigen. The untemplated addition of nucleotides during CDR3 recombination makes this region of the TCR chains critical to generating the vast diversity necessary for binding to a broad array of antigens. Some CDR3 sequences are considered "public" and are shared among $\mathrm{T}$ cells from different individuals whereas "private" sequences are specific to the individual (Madi et al. 2014), but both have a variety of lengths and D and J gene usage. Many of the caprine TCR genes that contribute to the CDR3 had homologues with bovine genes, but there were also unique caprine genes. Like in pigs (Uenishi et al. 2009), goats have more TRDD genes all with functional RSS upstream and downstream sequences than cattle as well as more TRDJ genes which overall could add CDR3 diversity. This may be especially emportant since there are fewer caprine TRDV1 genes. However, the addition of more caprine TRGJ genes may not add diversity since they appear to be duplication events rather than unique genes.

Goats have been found to express WC1 on subpopulations of $\gamma \delta \mathrm{T}$ cells in the same way as reported for cattle, and it has been shown that these cells participate in immune responses to pathogens (Yirsaw and Baldwin 2020). In cattle, we have shown that $\gamma \delta \mathrm{T}$ cells that express the co-receptor WC1 use a restricted set of genes to code for the TCR $\gamma$ chain while $\mathrm{WC1}^{-} \gamma \delta \mathrm{T}$ cells use all of the TCR genes available (Blumerman et al. 2006). This implies that the restriction is important for $\mathrm{WC}^{+}$cell function especially since the predicted structure of the gene product expressed by $\mathrm{WC}^{+}$ $\gamma \delta$ T cells (i.e., TRGC5) is substantially different from those of the other TRGC genes. We confirmed that this also occurs for the caprine $\gamma \delta \mathrm{T}$ cell populations and showed that goats have similar organization of the TRGC5 cassette as cattle and sheep (Conrad et al. 2007; Vaccarelli et al. 2005). Conservation of organization and usage implies an important role for its gene products in immune function to combat shared pathogens. Indeed, TRGC5 has been referred to as an ancient cassette among bovine, ovine, and dromedary implying that other cassettes coding for the TCR $\gamma$ chain are duplications of it (Antonacci et al. 2020a, 2020b; Vaccarelli et al. 2008). We have hypothesized that the restricted use of a particular TCR chain is because of the need for it to physically interact with WC1 to augment cell signaling in response to pathogens since WC1 and the TCR need to be co-ligated for there to be augmented signaling (Chen et al. 2014; Hanby-Flarida et al. 1996). A similar paradigm has been proven for the interaction of the TCR $\alpha$ chain with the accessory signaling molecules CD3 where the membrane proximal portion of the TCR $\alpha$ constant region controls signaling with the CD3 complex (Backstrom et al. 1996). If true, we would also expect other species that express WC1, such as pigs, to have an analogous if not homologous TRGC5.

In summary, $\gamma \delta \mathrm{T}$ cells may play different roles in ruminants than in humans and mice. However, much is still unknown about the function of $\gamma \delta \mathrm{T}$ cells in goats particularly. Our work here defining the goat $\gamma \delta$ TCR loci will allow us to form hypotheses regarding the functional equivalence between caprine and bovine $\gamma \delta \mathrm{T}$ cells since there are many basic studies with bovine $\gamma \delta$ T cells available to model this on (Baldwin et al. 2002; Blumerman et al. 2007; Meraviglia et al. 2011; Naiman et al. 2001, 2002; Rogers et al. 2005; Wang et al. 2011).

Supplementary Information The online version contains supplementary material available at https://doi.org/10.1007/s00251-021-01203-y.

Acknowledgments We would like to thank Dr. Amy Burnside, Institute of Applied Life Sciences at the University of Massachusetts Amherst, for assistance with the flow cytometry and Ms. Alice Newth, Livestock Learning Center at the University's Hadley Farm, for being accommodating and assisting with blood collection. The USDA is an equal opportunity provider and employer. The mention of trade names or commercial products in this publication is solely for the purpose of providing specific information and does not imply recommendation or endorsement by the US Department of Agriculture.

Author contributions AG and AY are co-first authors; they obtained and analyzed the genome annotation and gene sequence data; KG trained the computer program for genome annotation and chromosome mapping; TS and DB were involved in sequencing and assembling the caprine genome used here; MT constructed software programs to analyze the PacBio data; TC, JT, and CB conceived of the project, obtained funding, and supervised it. All authors contributed to writing the manuscript and constructing figures. 
Funding This work was funded by the US Department of Agriculture, National Institute for Food and Agriculture's Agriculture and Food Research initiative (AFRI-NIFA-USDA) grant no. 2015-06970. DB was supported by USDA appropriated project 509031000-026-00-D. TS was supported by USDA appropriated project 3040-31000-100-00-D.

Availability of data and material All data is available upon request.

\section{Compliance with ethical standards}

Ethics approval All work involving obtaining blood samples from cattle, goats, and sheep was approved by the University of Massachusetts' Animal Care and Use Committee.

Consent to publication All authors have agreed with the content of this publication.

\section{References}

Adams EJ, Chien YH, Garcia KC (2005) Structure of a gammadelta $\mathrm{T}$ cell receptor in complex with the nonclassical MHC T22. Sci 308:227-231

Antonacci R, Lanave C, Del Faro L, Vaccarelli G, Ciccarese S, Massari S (2005) Artiodactyl emergence is accompanied by the birth of an extensive pool of diverse germline TRDV1 genes. Immunogenetics 57:254-266

Antonacci R, Linguiti G, Burger PA, Castelli V, Pala A et al (2020a) Comprehensive genomic analysis of the dromedary $\mathrm{T}$ cell receptor gamma (TRG) locus and identification of a functional TRGC5 cassette. Dev Comp Immunol 106:103614

Antonacci R, Massari S, Linguiti G, Caputi Jambrenghi A, Giannico F, et al (2020b) Evolution of the T-Cell Receptor (TR) Loci in the Adaptive Immune Response: The Tale of the TRG Locus in Mammals. Genes (Basel) 11

Antonacci R, Vaccarelli G, Di Meo GP, Piccinni B, Miccoli MC et al (2007) Molecular in situ hybridization analysis of sheep and goat BAC clones identifies the transcriptional orientation of $\mathrm{T}$ cell receptor gamma genes on chromosome 4 in bovids. Vet Res Commun 31:977-983

Backstrom BT, Milia E, Peter A, Jaureguiberry B, Baldari CT, Palmer E et al (1996) A motif within the T cell receptor alpha chain constant region connecting peptide domain controls antigen responsiveness. Immun 5:437-447

Baldwin CL, Sathiyaseelan T, Naiman B, White AM, Brown R et al (2002) Activation of bovine peripheral blood gammadelta $\mathrm{T}$ cells for cell division and IFN-gamma production. Vet Immunol Immunopathol 87:251-259

Bickhart DM, Rosen BD, Koren S, Sayre BL, Hastie AR et al (2017) Single-molecule sequencing and chromatin conformation capture enable de novo reference assembly of the domestic goat genome. Nat Genet 49:643-650

Blumerman SL, Herzig CT, Baldwin CL (2007) WC1+ gammadelta T cell memory population is induced by killed bacterial vaccine. Eur J Immunol 37:1204-1216

Blumerman SL, Herzig CT, Rogers AN, Telfer JC, Baldwin CL (2006) Differential TCR gene usage between WC1- and WC1+ ruminant gammadelta $\mathrm{T}$ cell subpopulations including those responding to bacterial antigen. Immunogenetics 58:680-692

Campbell MS, Holt C, Moore B, Yandell M (2014) Genome annotation and curation using MAKER and MAKER-P. Curr Protoc Bioinform 48:4-11
Chen C, Hsu H, Hudgens E, Telfer JC, Baldwin CL (2014) Signal transduction by different forms of the gammadelta $\mathrm{T}$ cell-specific pattern recognition receptor WC1. J Immunol 193:379-390

Chen H, Kshirsagar S, Jensen I, Lau K, Covarrubias R et al (2009) Characterization of arrangement and expression of the $\mathrm{T}$ cell receptor gamma locus in the sandbar shark. Proc Natl Acad Sci USA 106:8591-8596

Connelley TK, Degnan K, Longhi CW, Morrison WI (2014) Genomic analysis offers insights into the evolution of the bovine TRA/TRD locus. BMC Genomics 15:994

Conrad ML, Mawer MA, Lefranc MP, McKinnell L, Whitehead J et al (2007) The genomic sequence of the bovine T cell receptor gamma TRG loci and localization of the TRGC5 cassette. Vet Immunol Immunopathol 115:346-356

Damani-Yokota P, Gillespie A, Pasman Y, Merico D, Connelley TK et al (2018) Bovine T cell receptors and gammadelta WC1 coreceptor transcriptome analysis during the first month of life. Dev Comp Immunol 88:190-199

Davis WC, Naessens J, Brown WC, Ellis JA, Hamilton MJ et al (1996) Analysis of monoclonal antibodies reactive with molecules upregulated or expressed only on activated lymphocytes. Vet Immunol Immunopathol 52:301-311

Dereeper A, Audic S, Claverie JM, Blanc G (2010) BLASTEXPLORER helps you building datasets for phylogenetic analysis. BMC EvolBiol 10:8

Dereeper A, Guignon V, Blanc G, Audic S, Buffet S et al (2008) Phylogeny.fr: robust phylogenetic analysis for the non-specialist. Nucleic Acids Res 36:W465-W469

Gellert M (2002) V(D)J recombination: RAG proteins, repair factors, and regulation. Annu Rev Biochem 71:101-132

Giannico F, Massari S, Jambrenghi AC, Soriano A, Pala A et al (2020) The expansion of the TRB and TRG genes indomestic goats (Capra hircus) is characteristic of the ruminant species. BMC Genomics 21:17

Hanby-Flarida MD, Trask OJ, Yang TJ, Baldwin CL (1996) Modulation of WC1, a lineage-specific cell surface molecule of gamma/ delta $\mathrm{T}$ cells augments cellular proliferation. Immunology $88: 116-123$

Hassanin A, Golub R, Lewis SM, Wu GE (2000) Evolution of the recombination signal sequences in the Ig heavy-chain variable region locus of mammals. Proc Natl Acad Sci USA 97:11415-11420

Hein WR, Mackay CR (1991) Prominence of gamma delta T cells in the ruminant immune system. Immunol Today 12:30-34

Herzig CT, Lefranc MP, Baldwin CL (2010) Annotation and classification of the bovine $\mathrm{T}$ cell receptor delta genes. BMC Genomics $11: 100$

Herzig CT, Mailloux VL, Baldwin CL (2015) Spectratype analysis of the $\mathrm{T}$ cell receptor delta CDR3 region of bovine gammadelta $\mathrm{T}$ cells responding to leptospira. Immunogenetics 67:95-109

Ishiguro N, Aida Y, Shinagawa T, Shinagawa M (1993) Molecular structures of cattle T-cell receptor gamma and delta chains predominantly expressed on peripheral blood lymphocytes. Immunogenetics 38:437-443

Krangel MS (2009) Mechanics of T cell receptor gene rearrangement. CurrOpinImmunol 21:133-139

Lahmers KK, Norimine J, Abrahamsen MS, Palmer GH, Brown WC (2005) The CD4+ T cell immunodominantAnaplasmamarginale major surface protein 2 stimulates gammadelta $\mathrm{T}$ cell clones that express unique T cell receptors. J Leukoc Biol 77:199-208

Lewis SE, Searle SM, Harris N, Gibson M, Lyer V et al (2002) Apollo: a sequence annotation editor. Genome Biol 3(12):1-4

Luoma AM, Castro CD, Mayassi T, Bembinster LA, Bai L et al (2013) Crystal structure of Vdelta1 T cell receptor in complex with CD1d-sulfatide shows MHC-like recognition of a self-lipid by human gammadelta T cells. Immun 39:1032-1042 
Mackay CR, Hein WR (1989) A large proportion of bovine T cells express the gamma delta $T$ cell receptor and show a distinct tissue distribution and surface phenotype. Int Immunol 1:540-545

Madi A, Shifrut E, Reich-Zeliger S, Gal H, Best K et al (2014) T-cell receptor repertoires share a restricted set of public and abundant CDR3 sequences that are associated with self-related immunity. Genome Res 24:1603-1612

Mamedov IZ, Britanova OV, Zvyagin IV, Turchaninova MA, Bolotin DA et al (2013) Preparing unbiased T-cell receptor and antibody cDNA libraries for the deep next generation sequencing profiling. Front Immunol 4:456

McGill JL, Sacco RE, Baldwin CL, Telfer JC, Palmer MV, Waters WR et al (2014) Specific recognition of mycobacterial protein and peptide antigens by gammadelta $\mathrm{T}$ cell subsets following infection with virulent Mycobacterium bovis. J Immunol 192:2756-2769

Meraviglia S, El Daker S, Dieli F, Martini F, Martino A (2011) gammadelta $\mathrm{T}$ cells cross-link innate and adaptive immunity in Mycobacterium tuberculosis infection. Clin Dev Immunol 2011:587315

Miccoli MC, Antonacci R, Vaccarelli G, Lanave C, Massari S et al (2003) Evolution of TRG clusters in cattle and sheep genomes as drawn from the structural analysis of the ovine TRG2@ locus. J Mol Evol 57:52-62

Naiman BM, Alt D, Bolin CA, Zuerner R, Baldwin CL (2001) Protective killed Leptospiraborgpetersenii vaccine induces potent $\mathrm{Th} 1 \mathrm{immu}-$ nity comprising responses by CD4 and gammadelta $\mathrm{T}$ lymphocytes. Infect Immun 69:7550-7558

Naiman BM, Blumerman S, Alt D, Bolin CA, Brown R et al (2002) Evaluation of type 1 immune response in naive and vaccinated animals following challenge with LeptospiraborgpeterseniiserovarHardjo: involvement of $\mathrm{WC1}(+)$ gammadelta and CD4 T cells. Infect Immun 70:6147-6157

Parra ZE, Baker ML, Hathaway J, Lopez AM, Trujillo J et al (2008) Comparative genomic analysis and evolution of the $\mathrm{T}$ cell receptor loci in the opossum Monodelphisdomestica. BMC Genomics 9:111

Piccinni B, Massari S, CaputiJambrenghi A, Giannico F, Lefranc MP et al (2015) Sheep (Ovisaries) T cell receptor alpha (TRA) and delta (TRD) genes and genomic organization of the TRA/TRD locus. BMC Genomics 16:709

Rogers AN, Vanburen DG, Hedblom EE, Tilahun ME, Telfer JC, Baldwin CL et al (2005) Gammadelta T cell function varies with the expressed WC1 coreceptor. J Immunol 174:3386-3393

Schwartz JC, Philp RL, Bickhart DM, Smith TPL, Hammond JA (2018) The antibody loci of the domestic goat (Capra hircus). Immunogenetics 70:317-326

Schwartz JC, Sanderson ND, Bickhart DM, Smith TPL, Hammond JA (2019) The structure, evolution, and gene expression within the caprine leukocyte receptor complex. Front Immunol 10:2302

Sowder JT, Chen CL, Ager LL, Chan MM, Cooper MD (1988) A large subpopulation of avian T cells express a homologue of the mammalian T gamma/delta receptor. J Exp Med 167:315-322

Takamatsu HH, Denyer MS, Stirling C, Cox S, Aggarwal N et al (2006) Porcine gammadelta $\mathrm{T}$ cells: possible roles on the innate and adaptive immune responses following virus infection. Vet Immunol Immunopathol 112:49-61

Uenishi H, Eguchi-Ogawa T, Toki D, Morozumi T, Tanaka-Matsuda $M$ et al (2009) Genomic sequence encoding diversity segments of the pig TCR delta chain gene demonstrates productivity of highly diversified repertoire. Mol Immunol 46:1212-1221

Vaccarelli G, Miccoli MC, Antonacci R, Pesole G, Ciccarese S (2008) Genomic organization and recombinational unit duplicationdriven evolution of ovine and bovine $\mathrm{T}$ cell receptor gamma loci. BMC Genomics 9:81

Vaccarelli G, Miccoli MC, Lanave C, Massari S, Cribiu EP, Ciccarese S et al (2005) Genomic organization of the sheep TRG1@ locus and comparative analyses of Bovidae and human variable genes. Gene 357:103-114

Van Rhijn I, Spiering R, Smits M, van Blokland MT, de Weger R et al (2007) Highly diverse TCR delta chain repertoire in bovine tissues due to the use of up to four D segments per delta chain. Mol Immunol 44:3155-3161

Wang F, Herzig CT, Chen C, Hsu H, Baldwin CL, Telfer JC et al (2011) Scavenger receptor WC1 contributes to the gammadelta $\mathrm{T}$ cell response to Leptospira. Mol Immunol 48:801-809

Washington EA, Kimpton WG, Cahill RN (1992) Changes in the distribution of alpha beta and gamma delta $\mathrm{T}$ cells in blood and in lymph nodes from fetal and postnatal lambs. Dev Comp Immunol 16:493-501

Wei Z, Lieber MR (1993) Lymphoid V(D)J recombination. Functional analysis of the spacer sequence within the recombination signal. J Biol Chem 268:3180-3183

Willcox CR, Vantourout P, Salim M, Zlatareva I, Melandri D et al (2019) Butyrophilin-like 3 directly binds a human Vgamma4(+) $\mathrm{T}$ cell receptor using a modality distinct from clonally-restricted antigen. Immun 51(813-25):e4

Yang YG, Ohta S, Yamada S, Shimizu M, Takagaki Y (1995) Diversity of T cell receptor delta-chain cDNA in the thymus of a onemonth-old pig. J Immunol 155:1981-1993

Yang Z, Sun Y, Ma Y, Li Z, Zhao Y et al (2017) A comprehensive analysis of the germline and expressed TCR repertoire in White Peking duck. Sci Rep 7:41426

Yirsaw A, Baldwin CL (2020) Goat gamma delta T cells. Dev Comp Immunol 114:15

Yirsaw AW, Gillespie A, Britton E, Doerle A, Johnson L, Marston S, Telfer JC, Baldwin CL et al (2021) Goat $\gamma \delta$ T cell subpopulations defined by $\mathrm{WC} 1$ gene expression, responses to pathogens and cytokine expression. Dev Comp Immunol

Publisher's Note Springer Nature remains neutral with regard to jurisdictional claims in published maps and institutional affiliations. 